\title{
Anammox bacteria in different compartments of recirculating aquaculture systems
}

\author{
Maartje A.H.J. van Kessel" ${ }^{1}{ }^{1}$, Harry R. Harhangi", Gert Flik†, Mike S.M. Jetten", Peter H.M. Klaren† and \\ Huub J.M. Op den Camp" \\ "Department of Microbiology, IWWR, Radboud University Nijmegen, Heyendaalseweg 135, NL-6525 AJ, Nijmegen, The Netherlands, and †Department of \\ Animal Physiology, IWWR, Radboud University Nijmegen, Heyendaalseweg 135, NL-6525 AJ, Nijmegen, The Netherlands
}

\begin{abstract}
Strict environmental restrictions force the aquaculture industry to guarantee optimal water quality for fish production in a sustainable manner. The implementation of anammox (anaerobic ammonium oxidation) in biofilters would result in the conversion of both ammonium and nitrite (both toxic to aquatic animals) into harmless dinitrogen gas. Both marine and freshwater aquaculture systems contain populations of anammox bacteria. These bacteria are also present in the faeces of freshwater and marine fish. Interestingly, a new planctomycete species appears to be present in these recirculation systems too. Further exploitation of anammox bacteria in different compartments of aquaculture systems can lead to a more environmentally friendly aquaculture practice.
\end{abstract}

\section{Nitrogenous waste in aquaculture systems}

Fish culture is generally practised in open waters. The release of nutrients or nutrient-rich water into the environment leads to eutrophication of the surrounding water. Furthermore, the spread of diseases between wild and cultured animals [1] and the escape of the cultured fish [1] led to an increased demand for closed aquaculture systems. Nowadays, fish aquaculture in The Netherlands is mostly carried out in closed recirculating aquaculture systems. A major problem in these systems is the maintenance of a constant and optimal water quality $[2,3]$. The most important pollutants in these systems are nitrogen compounds, mostly in the form of ammonium, which is produced in high amounts by cultured fish as a consequence of their high-protein diets [4]. The removal of ammonium from the aquaculture system is important since ammonium is toxic to fish. The concentration of ammonium, nitrite and other toxic compounds in the water can be kept at low levels by water exchange, which consumes large volumes of water [5] and is therefore very expensive. In addition to economic reasons, strict environmental legislation on concentrations of different compounds, especially ammonium and nitrite, in the effluent water [3] forces the aquaculture industry to invest in more efficient nitrogen-removal systems.

Most aquaculture systems use biofilters to lower the concentration of nitrogenous compounds in the effluent water. In these biofilters, microbial conversion is used to convert ammonium into less toxic nitrate [2], which is then removed by water exchange. Since the legislation for nitrate release becomes increasingly strict, the ultimate goal of aquaculture is now the complete removal of nitrogen compounds, including nitrate, from the system. Denitrific-

Key words: anaerobic ammonium oxidation (anammox), aquaculture, nitrogen removal, Planctomycetes, recirculating aquaculture system.

Abbreviations used: anammox, anaerobic ammonium oxidation; FISH, fluorescence in situ hybridization; PVC, Planctomycetes/Verrucomicrobia/Chlamydiae.

${ }^{1}$ To whom correspondence should be addressed (email Maartje.vankessel@science.ru.nl). ation, the anaerobic conversion of nitrate into dinitrogen gas, is considered by some as the most suitable biological pathway to remove nitrate [5]. However, the need to supply organic compounds that function as electron donors for this process is problematic in many aquaculture settings. Furthermore, intermediates in the conversion of nitrate into dinitrogen gas, especially nitrous oxide, are toxic to fish and other aquatic animals. For these reasons, the application of denitrification in full-scale aquaculture systems is difficult. Another possibility for the complete removal of ammonium is partial nitrification followed by anammox (anaerobic ammonium oxidation). This simultaneous activity has been shown already for both natural and man-made ecosystems [6-8]. Bacteria performing anammox oxidize ammonium under anoxic conditions by the use of nitrite, which yields dinitrogen gas. The process does not consume oxygen and is therefore $50 \%$ less oxygen-demanding compared with conventional nitrification-denitrification processes [9]. Further advantages of the anammox reaction are that it does not need an additional electron donor for the removal of ammonium [10] and the fact that no toxic intermediates are released into the water.

In the present paper, we briefly review the role of anammox in biofiltration in aquaculture systems. Furthermore, we discuss the possible origin of the anammox bacteria in these systems. It also appears that aquaculture systems can be enriched in a certain type of anammox cells, which possibly form a new subgroup within the known Planctomycetes. We finally suggest some solutions to improve biofiltration in aquaculture systems by the use of the anammox process.

\section{Biofiltration and anammox in aquaculture systems}

The existence of bacteria performing the anammox reaction was only discovered in the late 1990s in a wastewatertreatment plant in The Netherlands [11], and, since then, the 
Figure 1 Anammox bacteria in different aquaculture systems (900 and 3000 litre) and in the faeces of common carp and representatives of the PVC superphylum

The tree was calculated using the Neighbour-joining algorithm with Kimura 2-parameter correction. Bootstrap values of 500 replicates are shown at the nodes. The scale bar represents 0.05 nucleotide changes per position. Genomic DNA was isolated from filter material and fish faeces, and PCRs targeting the 16S rRNA gene of anammox bacteria (Pla46 [30] × Amx820 [35]) were performed.

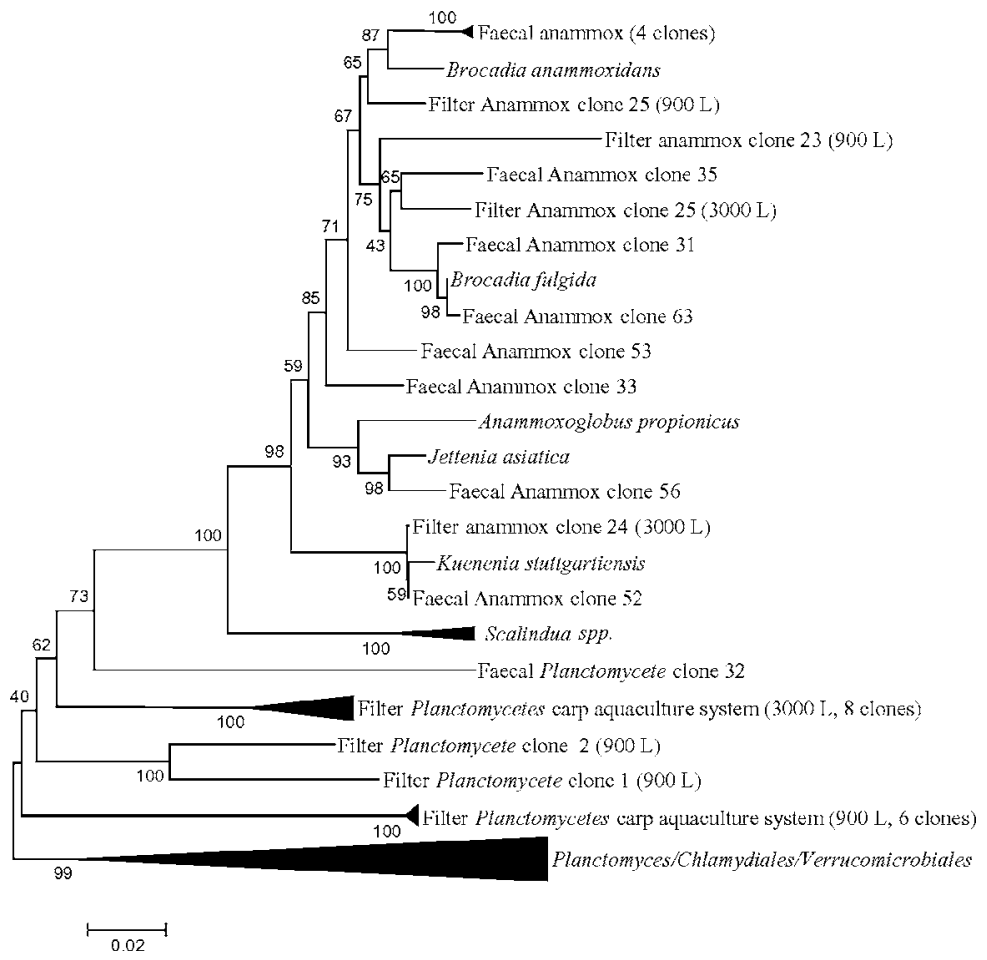

process has been shown to play an important role in nitrogen losses in many different natural and man-made ecosystems, including marine ecosystems [8] and freshwater lakes [12]. The presence of anammox bacteria in both natural and manmade ecosystems would suggest that these bacteria can also survive and function in aquaculture systems. There is some evidence for the presence of these bacteria in aquaculture systems.

The first study demonstrating the presence of ammoniumoxidizing bacteria in aquaculture systems was performed by Tal et al. $[13,14]$. They were able to measure anammox activity and to visualize anammox cells by the use of FISH (fluorescence in situ hybridization) in an enrichment culture obtained from the biofilter of a recirculating aquaculture system [14]. The first evidence for anammox bacteria in freshwater ecosystems was obtained recently [15] (Figure 1). Both studies showed the presence of known anammox species, i.e. Candidatus 'Brocadia' and Candidatus 'Kuenenia' species in the filter systems of aquaculture systems. Interestingly, there were also sequences found that form a subgroup between the anammox bacteria and the other members of the PVC (Planctomycetes/Verrucomicrobia/Chlamydiae) superphylum. The activity of anammox bacteria could not be measured but the use of specific primers targeting the $16 \mathrm{~S}$
rRNA gene resulted in gene amplification of the anammox 16S rRNA gene [15]. Assays that measure anammox activity directly are usually not applicable in these samples since the number of anammox bacteria in aquaculture systems is low; enrichments are needed to actually show anammox activity. The low population density is probably caused by the high aeration in most aquaculture settings. Most biofilters are developed for efficient nitrification, the conversion of ammonium into nitrate, which is oxygen-dependent. Anammox bacteria are inhibited by the presence of oxygen [16], but can be detected in the aerated systems $[13,15]$. They are probably present in the anoxic zones of aerated biofilters. For example, in trickling filters, where water is pumped through the filter without additional aeration in the filter tank, an oxygen gradient is formed by the activity of oxygenconsuming organisms.

However, also in highly aerated filter systems, anammox bacteria can be detected by PCR ([15], and M.A.H.J. van Kessel, personal observation in carp aquaculture systems). Also in these systems, zones with low oxygen concentrations exist, and the anammox bacteria most probably reside in the biofilm present on the filter material. Oxygen-free zones are created by the oxygen consumption and limited penetration of oxygen through a bacterial biofilm, since it is assumed 
that oxygen cannot penetrate a bacterial biofilm further than 100-200 $\mu \mathrm{m}[17,18]$.

The existence of different nitrogen-cycling bacteria in a biofilm has been elegantly demonstrated [19]. Ammoniumoxidizing bacteria, which consume oxygen, were located on the outside of the biofilm of a rotating biological contactor treating ammonium-rich leachate. Anammox bacteria were found to be located inside the biofilm, in places assumed to be oxygen-depleted. Furthermore, nitrite-oxidizing bacteria were present in the same biofilm [19]. The presence of ammonium-oxidizing bacteria near anammox bacteria has a second great benefit, since these organisms supply the nitrite by the oxidation of ammonium. Nitrite is required by anammox bacteria to oxidize ammonium and is generally only present at low concentrations. In aquaculture systems, anammox bacteria are probably simultaneously active with ammonium-oxidizing bacteria or archaea. This simultaneous activity has been shown already in other ecosystems, both natural and man-made $[6-8,20]$. The coexistence of ammonium- and nitrite-oxidizing bacteria and anammox would be ideal in a biofilter for aquaculture systems.

\section{Anammox in fish intestines}

Biofilters generally have short solid-retention times and high fluxes of water. Despite the slow doubling time of anammox bacteria [21], activity has been measured in biofilters with a short solid-retention time and was found to be the to biofilters with a long solid-retention time [22]. Therefore Lahav et al. [22] hypothesized that the biofilters of the recirculating aquaculture system they investigated were seeded by anammox via another source within the aquaculture system. The most plausible source would be fish faeces which are released into the water and contain very high numbers of bacteria. Indeed, anammox bacteria were present in the faeces of sea bream as shown by FISH analysis [22]. Also, the faeces of common carp (Cyprinus carpio L.) contain anammox bacteria, as shown by PCR analysis using specific primers targeting the $16 \mathrm{~S}$ rRNA gene of anammox bacteria (M.A.H.J. van Kessel, unpublished work) (Figure 1).

The studies mentioned above, showing the presence of anammox bacteria in fish intestines, are the only proof for the presence of anammox bacteria inside a vertebrate body known to date; the presence of anammox bacteria in the fish gut has not been investigated in detail. To date, the composition of the intestinal microbiota of fish has been studied for a long time and culture-dependent methods were often used. However, owing to the long division time and the inhibition by oxygen, it is difficult to show the presence of anammox bacteria using these methods. Nowadays, culture-independent studies, mainly surveys of the $16 \mathrm{~S}$ rRNA sequences in the investigated systems are becoming increasingly important, despite the constant validation and development of new primers targeting the 16S rRNA gene. Planctomycetes show mismatches for the primers targeting general bacterial $16 \mathrm{~S}$ rRNA $[23,24]$. However, it was shown that the microbiota of fish intestines comprised planctomycete sequences $[25,26]$. Molecular analysis could not be done in great detail as these sequences were relatively short, which makes it difficult to conclude whether the sequences obtained were truly anammox-specific. Other aquatic animals, mainly invertebrates, appear to harbour Planctomycetes in their intestines [27] as well, or are otherwise associated with Planctomycetes [28]. Planctomycetes have also been shown to be associated with kelp [29]. However, these sequences often belong to one of the other orders within the Planctomycetes [27], indicating that the Planctomycetes are a highly diverse group which can live in association (possibly in symbiosis) with higher organisms.

\section{Planctomycete subgroup}

Planctomycetes are highly abundant in aquatic ecosystems, both marine and freshwater [30]. Many planctomycete sequences are deposited in $\mathrm{GenBank}^{\circledR}$, but almost all are obtained from molecular surveys without culturing. As mentioned above, the investigated filter systems also contained planctomycete sequences which form a different subgroup in phylogenetic trees [15] (Figure 1). The function of these organisms and the reactions they perform are not yet known. A study of planctomycete communities in lentic freshwater ecosystems revealed that all sequences sharing $\geqslant 98 \%$ sequence identity with sequences from GenBank ${ }^{\circledR}$ were closely related to environmental sequences and not to cultivated organisms [31]. Taking into account that $46 \%$ of the OTUs (operational taxonomic units) displayed sequence similarity $<98 \%$ with sequences from GenBank ${ }^{\circledR}$, it can be concluded that the Planctomycetes from freshwater ecosystems are still poorly known.

Furthermore, the sequences found in the filter systems we investigated (Figure 1) showed low similarity to known sequences, which were all from non-cultured organisms (Table 1). The sequences similar to the sequences in our aquaculture systems were all obtained from freshwater ecosystems, especially wastewater-treatment plants and aquaculture systems [14,22,32] from all over the world, including South Korea, China, Austria and France. However, it is difficult to compare the concentrations of possible metabolites for these organisms in the different systems investigated. Not all sequences are supported by publications, so information about the concentrations of nitrogenous and other compounds is scarce. However, sometimes the occurrence of nitrogen removal is explicitly mentioned. In the aquaculture systems we investigated, nitrogen concentration is low. Ammonium was present in the $1-10 \mu \mathrm{M}$ range, and concentrations of nitrite were below $10 \mu \mathrm{M}$. It is very possible that the organisms found in these systems are adapted to low substrate concentrations. If so, these organisms would be much more suitable for the removal of nitrogen from aquaculture systems. More research is needed find out more about the nature of this planctomycete subgroup. 
Table 1 | Sequences most similar to sequences of the Planctomycetes-related subgroup obtained from an aquaculture system A BLAST search was performed with clone HRH693 (HM234117).

\begin{tabular}{lllll}
\hline Accession number & Identity (\%) & Country & Nitrogen concentration & Reference \\
\hline FJ208830 & $94 / 97$ & South Korea & No information available & - \\
BX294814 & 98 & France & No information available & {$[33]$} \\
GQ356083 & 95 & Austria & $\mathrm{NH}_{4}+=27 \pm 11 \mathrm{mM}_{;} \mathrm{NO}_{2}^{-}=11 \pm 5 \mathrm{mM}$ & {$[34]$} \\
GU327807 & 90 & China & No information available & - \\
\hline
\end{tabular}

\section{Conclusions}

Since the discovery of anammox bacteria in the late 1990s, their presence and importance has been shown in many different ecosystems. The presence of anammox bacteria in the biofilters in aquaculture systems can be very important to aquaculture industry, since the anammox bacteria can remove ammonium and nitrite, both toxic to aquatic animals, simultaneously. The presence of these bacteria in biofilter systems of different aquaculture systems suggests that anammox can be incorporated in biofiltration. However, these systems may have to be adapted to allow a more efficient growth of anammox cells. These slow-growing organisms are inhibited by oxygen, therefore biofilters in aquaculture systems should have oxygen-minimum zones. These zones should not be fully depleted of oxygen since the simultaneous activity of ammonium oxidizing bacteria is needed for the production of nitrite. The only source for nitrite needed by the anammox bacteria is via aerobic ammonium oxidation. With this partial nitrification-anammox system, nitrogenous waste can completely removed from the system in an environmentally friendly manner, since nitrogen gas is formed without the need for an additional electron donor.

Furthermore, the presence of anammox bacteria in the guts of fish could open doors to the seeding on biofilters with anammox bacteria. If conditions are created in which anammox can grow on biofilters, biofilms inhabiting ammoniumoxidizing, nitrite-oxidizing and anammox bacteria can grow themselves. Finally, the presence of new planctomycete sequences in these systems can lead to the discovery of new organisms suitable for biofiltration. However, the nature of these organisms has to be investigated further, since their metabolism and function remain unsolved to date.

Biofiltration in aquaculture remains an important research topic for the near future. Implementation of novel fundamental knowledge into new technology may help to optimize the management of nitrogenous waste in aquaculture.

\section{Acknowledgements}

We thank Tom Spanings from the Department of Animal Physiology (Radboud University Nijmegen) for biofilter and aquaculture system maintenance.

\section{Funding}

M.S.M.J. and M.A.H.J.v.K. are supported by the European Research Council [grant number 232937].

\section{References}

1 Boyd, C.E., McNevin, A.A., Clay, J. and Johnson, H.M. (2005) Certification issues for some common aquaculture species. Rev. Fish. Sci. 13, 231-279

2 Crab, R., Avnimelech, Y., Defoirdt, T., Bossier, P. and Verstraete, W. (2007) Nitrogen removal techniques in aquaculture for a sustainable production. Aquaculture 270, 1-14

3 van Rijn, J. (1996) The potential of integrated biological treatment systems in recirculating fish culture. Aquaculture 139, 181-201

4 Mommsen, T.P. and Walsh, P.J. (1992) Biochemical and environmental perspectives on nitrogen-metabolism in fishes. Experientia 48, 583-593

5 Hargreaves, J.A. (1998) Nitrogen biogeochemistry of aquaculture ponds. Aquaculture 166, 181-212

6 Sliekers, A.0., Derwort, N., Gomez, J.L.C., Strous, M., Kuenen, J.G. and Jetten, M.S.M. (2002) Completely autotrophic nitrogen removal over nitrite in one single reactor. Water Res. 36, 2475-2482

7 Lam, P., Jensen, M.M., Lavik, G., McGinnis, D.F., Muller, B., Schubert, C.J., Amann, R., Thamdrup, B. and Kuypers, M.M.M. (2007) Linking crenarchaeal and bacterial nitrification to anammox in the Black Sea. Proc. Natl. Acad. Sci. U.S.A. 104, 7104-7109

8 Lam, P., Lavik, G., Jensen, M.M., van de Vossenberg, J., Schmid, M., Woebken, D., Dimitri, G., Amann, R., Jetten, M.S.M. and Kuypers, M.M.M. (2009) Revising the nitrogen cycle in the Peruvian oxygen minimum zone. Proc. Natl. Acad. Sci. U.S.A. 106, 4752-4757

9 Jetten, M.S.M., Wagner, M., Fuerst, J., van Loosdrecht, M., Kuenen, G. and Strous, M. (2001) Microbiology and application of the anaerobic ammonium oxidation ('anammox') process. Curr. Opin. Biotechnol. 12, 283-288

10 Jetten, M.S.M., van Niftrik, L., Strous, M., Kartal, B., Keltjens, J.T. and Op den Camp, H.J.M. (2009) Biochemistry and molecular biology of anammox bacteria. Crit. Rev. Biochem. Mol. Biol. 44, 65-84

11 Mulder, A., Vandegraaf, A.A., Robertson, L.A. and Kuenen, J.G. (1995) Anaerobic ammonium oxidation discovered in a denitrifying fluidized-bed reactor. FEMS Microbiol. Ecol. 16, 177-183

12 Schubert, C.J., Durisch-Kaiser, E., Wehrli, B., Thamdrup, B., Lam, P. and Kuypers, M.M.M. (2006) Anaerobic ammonium oxidation in a tropical freshwater system (Lake Tanganyika). Environ. Microbiol. 8, 1857-1863

13 Tal, Y., Watts, J.E.M., Schreier, S.B., Sowers, K.R. and Schreier, H.J. (2003) Characterization of the microbial community and nitrogen transformation processes associated with moving bed bioreactors in a closed recirculated mariculture system. Aquaculture 215, 187-202

14 Tal, Y., Watts, J.E. and Schreier, H.). (2006) Anaerobic ammonium-oxidizing (anammox) bacteria and associated activity in fixed-film biofilters of a marine recirculating aquaculture system. Appl. Environ. Microbiol. 72, 2896-2904

15 van Kessel, M.A.H.J., Harhangi, H.R., van de Pas-Schoonen, K., van de Vossenberg, J., Flik, G., Jetten, M.S.M., Klaren, P.H.M. and op den Camp, H.J.M. (2010) Biodiversity of $\mathrm{N}$-cycle bacteria in nitrogen removing moving bed biofilters for freshwater recirculating aquaculture systems. Aquaculture 306, 177-184

16 Strous, M., Heijnen, J.J., Kuenen, J.G. and Jetten, M.S.M. (1998) The sequencing batch reactor as a powerful tool for the study of slowly growing anaerobic ammonium-oxidizing microorganisms. Appl. Microbiol. Biotechnol. 50, 589-596

17 Koch, G., Egli, K., Van der Meer, J.R. and Siegrist, H. (2000) Mathematical modeling of autotrophic denitrification in a nitrifying biofilm of a rotating biological contactor. Water Sci. Technol. 41, 191-198

18 Hao, X.D., Heijnen, J.J. and van Loosdrecht, M.C.M. (2002) Sensitivity analysis of a biofilm model describing a one-stage completely autotrophic nitrogen removal (CANON) process. Biotechnol. Bioeng. 77, 266-277 
19 Egli, K., Bosshard, F., Werlen, C., Lais, P., Siegrist, H., Zehnder, A.J.B. and van der Meer, J.R. (2003) Microbial composition and structure of a rotating biological contactor biofilm treating ammonium-rich wastewater without organic carbon. Microb. Ecol. 45, 419-432

20 Trimmer, M., Nicholls, J.C., Morley, N., Davies, C.A. and Aldridge, J. (2005) Biphasic behavior of anammox regulated by nitrite and nitrate in an estuarine sediment. Appl. Environ. Microbiol. 71, 1923-1930

21 van der Graaf, A.A., de Bruijn, P., Robertson, L.A., Jetten, M.S.M. and Kuenen, G. (1996) Autotrophic growth of anaerobic ammonium-oxidizing micro-organisms in a fluidized bed reactor. Microbiol. 142, 2187-2196

22 Lahav, 0., Bar Massada, I., Yackoubov, D., Zelikson, R., Mozes, N., Tal, Y. and Tarre, S. (2009) Quantification of anammox activity in a denitrification reactor for a recirculating aquaculture system. Aquaculture 288, 76-82

23 Chouari, R., Le Paslier, D., Daegelen, P., Ginestet, P., Weissenbach, J. and Sghir, A. (2005) Novel predominant archaeal and bacterial groups revealed by molecular analysis of an anaerobic sludge digester. Environ. Microbiol. 7, 1104-1115

24 Daims, H., Bruhl, A., Amann, R., Schleifer, K.H. and Wagner, M. (1999) The domain-specific probe EUB338 is insufficient for the detection of all Bacteria: development and evaluation of a more comprehensive probe set. Syst. Appl. Microbiol. 22, 434-444

25 Roeselers, G., Mittge, E.K., Stephens, W.Z., Parichy, D.M., Cavanaugh, C.M., Guillemin, K. and Rawls, J.F. (2011) Evidence for a core gut microbiota in the zebrafish. ISME J. 5, 1595-1608

26 Rawls, J.F., Mahowald, M.A., Ley, R.E. and Gordon, J.I. (2006) Reciprocal gut microbiota transplants from zebrafish and mice to germ-free recipients reveal host habitat selection. Cell 127, 423-433

27 Fuerst, J.A., Gwilliam, H.G., Lindsay, M., Lichanska, A., Belcher, C., Vickers, J.E. and Hugenholtz, P. (1997) Isolation and molecular identification of planctomycete bacteria from postlarvae of the giant tiger prawn, Penoeus monodon. Appl. Environ. Microbiol. 63, 254-262
28 Pimental-Elardo, S., Wehrl, M., Friedrich, A.B., Jensen, P.R. and Hentschel, U. (2003) Isolation from planctomycetes from Aplysino sponges. Aquat. Microb. Ecol. 33, 239-243

29 Bengtsson, M.M. and Ovreas, L. (2010) Planctomycetes dominate biofilms on surfaces of the kelp Laminaria hyperborea. BMC Microbiol. 10, $1-12$

30 Neef, A., Amann, R., Schlesner, H. and Schleifer, K.H. (1998) Monitoring a widespread bacterial group: in situ detection of planctomycetes with 165 rRNA-targeted probes. Microbiology 144, 3257-3266

31 Pollet, T., Tadonleke, R.D. and Humbert, J.F. (2011) Comparison of primer sets for the study of Planctomycetes communities in lentic freshwater ecosystems. Environmental Microbiol. Rep. 3, 254-261

32 Egli, K., Fanger, U., Alvarez, P.J.J., Siegrist, H., van der Meer, J.R. and Zehnder, A.J.B. (2001) Enrichment and characterization of an anammox bacterium from a rotating biological contactor treating ammonium-rich leachate. Arch. Microbiol. 175, 198-207

33 Chouari, R., Le Paslier, D., Daegelen, P., Ginestet, P., Weissenbach, J. and Sghir, A. (2003) Molecular evidence for novel planctomycete diversity in a municipal wastewater treatment plant. Appl. Environ. Microbiol. 69, 7354-7363

34 Park, H., Rosenthal, A., Ramalingam, K., Fillos, J. and Chandran, K. (2010) Linking community profiles, gene expression and $\mathrm{N}$-removal in anammox bioreactors treating municipal anaerobic digestion reject water. Environ. Sci. Technol. 44, 6110-6116

35 Schmid, M., Twachtmann, U., Klein, M., Strous, M., Juretschko, S., Jetten, M., Metzger, J.W., Schleifer, K.H. and Wagner, M. (2000) Molecular evidence for genus level diversity of bacteria capable of catalyzing anaerobic ammonium oxidation. Syst. Appl. Microbiol. 23, 93-106

Received 9 September 2011

doi:10.1042/BST20110743 